\title{
VOLATILIZAÇÃO DE AMÔNIA EM SOLOS ALAGADOS INFLUENCIADA PELA FORMA DE APLICAÇÃO DE UREIA $^{(1)}$
}

\author{
Ronaldir Knoblauch(2), Paulo Roberto Ernani( ${ }^{(3)}$, Timothy Wayne \\ Walker $^{(4)}$, Larry Jason Krutz ${ }^{(5)}$, Jac Jeremier Varco ${ }^{(6)}$, Luciano Colpo \\ Gatiboni $^{(7)} \&$ Francisco Carlos Deschamps $^{(8)}$
}

\begin{abstract}
RESUMO
A volatilização de amônia $\left(\mathrm{NH}_{3}\right)$ e a nitrificação seguida pela desnitrificação são os principais mecanismos de perdas de $\mathrm{N}$ nos solos alagados destinados ao cultivo do arroz. Se os fertilizantes nitrogenados não forem manejados adequadamente, os índices de recuperação de $\mathrm{N}$ pelas plantas serão muito baixos. O objetivo deste trabalho foi quantificar a volatilização de amônia em solos alagados influenciada pela forma de aplicação de ureia, em casa de vegetação. Foram conduzidos dois experimentos, sendo um em Cambissolo (Thermic Vertic Haplaquepts), no Estado do Mississippi, EUA, e outro em Gleissolo (Entisol Aeric Typic), em Santa Catarina, Brasil. A captação de amônia foi realizada por esponjas acidificadas, colocadas dentro de tubos de PVC (15 cm de diâmetro e $60 \mathrm{~cm}$ de altura) encravados dentro de baldes com $15 \mathrm{~cm}$ de espessura de solo, sem a presença de plantas. Em cada vaso, foram aplicados $353 \mathrm{mg} \mathrm{de} \mathrm{N}$, equivalente a $200 \mathrm{~kg} \mathrm{ha}^{-1}$ de $\mathrm{N}$, nas seguintes formas: ureia sólida aplicada sobre a superfície do solo úmido, sem alagamento posterior; ureia solubilizada em água deionizada e aplicada sobre a lâmina de água de alagamento; ureia sólida aplicada sobre a lâmina de água de alagamento; ureia incorporada na lama, seguida de alagamento; ureia aplicada sobre solo seco, seguida de alagamento $48 \mathrm{~h}$ depois; e uma testemunha alagada $(\operatorname{sem} \mathrm{N})$. As esponjas captadoras de amônia foram trocadas ao serem completados $1,3,6,9,13,17$ e 22 dias de alagamento, e nelas determinou-se a quantidade de amônia volatilizada. Na água de alagamento do
\end{abstract}

(1) Parte da Tese de Doutorado do primeiro autor, apresentada à Universidade do Estado de Santa Catarina - UDESC. Recebido para publicação em 4 de maio de 2011 e aprovado em 12 de abril de 2012.

(2) Doutorando em Manejo do Solo pela Universidade do Estado de Santa Catarina - UDESC. Av. Luiz de Camões 2090, CEP 88520000 Lages (SC). E-mail: ronaldirkn@gmail.com

(3) Professor do Departamento de Solos, UDESC. Pesquisador do CNPq. E-mail: prernani@cav.udesc.br

(4) Associate Agronomist, Mississippi State University, USA. E-mail: twalker@drec.msstate.edu

(5) Weed Science Researcher, United States Department of Agriculture, USA. E-mail: jason.krutz@ars.usda.gov

(6) Plant and Soil Sciences Dept., Mississippi State University, USA. E-mail: jvarco@pss.msstate.edu

(7) Professor do Departamento de Solos, UDESC. Pesquisador do CNPq. E-mail: lgatiboni@gmail.com

(8) Pesquisador da Epagri, Estação Experimental de Itajaí. E-mail: xicodsc@epagri.sc.gov.br 
solo, determinaram-se o pH e a concentração de amônio. A emissão de amônia variou com a forma de aplicação da ureia, e o comportamento foi similar nos dois solos. A volatilização de amônia na testemunha foi insignificante. Nos tratamentos com ureia, as menores perdas ocorreram quando ela foi incorporada na lama (com posterior alagamento) seguida pela aplicação em solo seco com alagamento $48 \mathrm{~h}$ após, tendo atingido, respectivamente, 4 e $15 \%$ do $\mathrm{N}$ aplicado no Cambissolo (CXbe) e 6 e $10 \%$ no Gleissolo (GXbd). As maiores perdas ocorreram quando a ureia foi aplicada na lâmina de água, tanto na forma líquida (34 \% no CXbe e 38 \% no GXbd) quanto na sólida (29 \% no CXbe e 37 \% no GXbd), seguida pela ureia aplicada em solo úmido, sem alagamento (26\% no CXbe e $22 \%$ no GXbd). A fim de evitar excessiva volatilização de amônia em solos cultivados com arroz no sistema inundado, a ureia deve ser aplicada na lama ou em condições de solo seco e, em ambos os casos, seguida de alagamento imediato.

Termos de indexação: adubação nitrogenada, arroz irrigado, perdas de N.

\title{
SUMMARY: AMMONIA VOLATILIZATION IN WATERLOGGED SOILS INFLUENCED BY THE FORM OF UREIA APPLICATION
}

\begin{abstract}
Ammonia volatilization and nitrification/denitrification are the two major $N$ loss mechanisms in rice production. If $N$ fertilizer is not managed appropriately, $N$ recovery by rice plants can be low. The purpose of this study was to quantify ammonia volatilization in flooded soils influenced by the urea application method. A greenhouse study was conducted to quantify the potential of $N$ loss via ammonia volatilization in flooded soils influenced by the urea application method. Two experiments were carried out, one in Mississippi, USA, with a thermic Vertic Haplaquepts and one in Santa Catarina, Brazil, with an Entisol Aeric soil, respectively. Ammonia was trapped in sponge sorbers impregnated with phosphoric acid and placed in PVC tubes (diameter $15 \mathrm{~cm}$, length $60 \mathrm{~cm}$ ), which were set in buckets containing a $15 \mathrm{~cm}$ soil layer without plants. Urea was applied at a rate of $353 \mathrm{mg} / \mathrm{pot}$ of $\mathrm{N}$, equivalent to $200 \mathrm{~kg} \mathrm{ha} \mathrm{h}^{-1} \mathrm{~N}$, as follows: 1) a non-treated control (0 N); 2) urea applied to the surface of moist soil (80\% of field capacity) without flooding; 3) urea solubilized in deionized water and applied to the flood water; 4) prilled urea, applied to the flood water; 5) urea incorporated into mud followed by soil flooding and 6) urea applied on the surface of a dry soil followed by flooding 48 hours later. The sorbers were exchanged 1, 3, 6, 9, 13, 17, and 22 days after urea application. Water $p H$ and ammonium concentration were determined in the flood water above the soil surface. Ammonia emission varied with the form of urea application, similarly in both soils. $N$ losses were negligible in the control. Losses were lowest when urea was incorporated into mud followed by soil flooding and second lowest when applied to dry soil followed by flooding $48 \mathrm{~h}$ later (losses of, respectively, 4 and $15 \%$ from the USA soil and 6 and $10 \%$ from the Brazilian soil). Losses were highest when urea was applied to the flood water, be it in liquid (34\% in Mississsippi and $38 \%$ in Santa Catarina) or in solid form (29\% in Mississsippi and $37 \%$ in Santa Catarina), followed by urea applied to wet soil without flooding (26\% in Mississsippi and $22 \%$ in Santa Catarina). In conclusion, to avoid excessive ammonia loss from waterlogged soils, urea should be incorporated into the mud or applied to dry soil, followed by immediate flooding in both cases.
\end{abstract}

Index terms: nitrogen fertilization, irrigated rice, $N$ losses.

\section{INTRODUÇÃO}

O nitrogênio é o nutriente requerido em maior quantidade pelo arroz irrigado (Oryza sativa L.) (Fageria et al., 2003; Mattos, 2004). Todavia, a di- nâmica desse elemento no solo é bastante complexa, devido à multiplicidade de formas químicas e às reações e processos aos quais ele está sujeito. Nos solos alagados, essas transformações são ainda mais complexas, em função da existência de uma lâmina 
de água sobre o solo, de uma fina camada oxidada na interface solo-água, seguida por uma camada reduzida abaixo desta, e de outra camada oxidada em torno das raízes do arroz (Ponnamperuma, 1972; Reddy \& Patrick, 1986). Isso se reflete diretamente sobre a eficiência de recuperação do $\mathrm{N}$ pelas plantas de arroz, que raramente excede $50 \%$ da quantidade aplicada (Scivittaro et al., 2002; Isherwood, 2003; Fageria et al., 2003).

Em razão do menor custo por unidade de $\mathrm{N}$ e da alta concentração do nutriente, a ureia é o fertilizante nitrogenado mais utilizado na agricultura brasileira (Cantarella, 2007). Apesar desses aspectos favoráveis, a dissolução da ureia apresenta reação inicial alcalina, o que favorece a volatilização de amônia para a atmosfera quando o fertilizante é aplicado sobre a superfície do solo ou sobre a lâmina de água, e essa é a principal perda de $\mathrm{N}$ em solos alagados, cultivados com arroz (Buresh, 2008). Vários fatores influenciam a intensidade desse tipo de perda em solos alagados, destacando-se atributos relativos à água de inundação $(\mathrm{pH}$, concentração de amônio $\left(\mathrm{NH}_{4}^{+}\right)$, pressão de $\mathrm{CO}_{2}$, temperatura, profundidade da lâmina e atividade das algas), ao solo $\left(\mathrm{pH}\right.$, pressão de $\mathrm{CO}_{2}$, capacidade de troca de cátions e atividade microbiana) e às condições atmosféricas (velocidade do vento, temperatura do ar e radiação solar). Além desses, outros fatores, como manejo da água, forma e tipo do fertilizante aplicado e estádio da cultura, alteram a taxa de volatilização de amônia em solos inundados (Vleck \& Craswell, 1981; Lindau et al., 1989; Watanabe et al., 2009). Vleck \& Craswll (1981) estudaram a composição química da lâmina de água sobre o solo e verificaram que $50 \%$ do $\mathrm{N}$ amoniacal se encontrava na forma de amônia em pH 9,2. A volatilização de amônia em arroz irrigado é muito variável: entre 7 e $47 \%$ na China, entre 9 e 39 \% nas Filipinas (Hayashi, 2006) e, no Rio Grande do Sul, de $15 \%$, quando aplicada em solo saturado, a $22 \%$, quando aplicada em solo seco (Scivittaro et al., 2005).

Até 2004, a recomendação de aplicação de $\mathrm{N}$ em cobertura para o arroz semeado em solo seco com posterior irrigação, nos Estados do Rio Grande do Sul e Santa Catarina, era de aplicar a ureia após o alagamento da lavoura. No sistema pré-germinado, a recomendação era para que todas as aplicações de ureia em cobertura fossem realizadas sobre a lâmina de água (CQFSRS/SC, 1995; IRGA, 2001). A nova recomendação de adubação nitrogenada para o arroz nessa região (CQFSRS/SC, 2004; SOSBAI, 2010) sugere, para o sistema de semeadura em solo seco com posterior irrigação, a aplicação da ureia antes do alagamento. Nesse caso, propõe-se o máximo de três dias entre a aplicação de ureia e o início da entrada de água na lavoura, para evitar possíveis perdas de N. Todavia, para o sistema pré- germinado, a recomendação continua indicando a aplicação da ureia sobre a lâmina de água.

Esses fatores relacionados com o manejo da água e com a forma de aplicação da ureia podem influenciar as perdas do $\mathrm{N}$ aplicado ao solo pelos fertilizantes, com consequências na eficiência de aproveitamento do nutriente pelas plantas e na produtividade do arroz. No Brasil, pouco se conhece sobre a volatilização de amônia em solos alagados, principalmente quando o arroz é cultivado no sistema pré-germinado.

O objetivo deste trabalho foi quantificar a volatilização de amônia em solos alagados influenciada pela forma de aplicação de ureia, em casa de vegetação.

\section{MATERIAL E MÉTODOS}

Foram conduzidos dois experimentos: um na Delta Research and Extension Center, da Mississippi State University, nos Estados Unidos, e outro na Estação Experimental da Empresa de Pesquisa Agropecuária e Extensão Rural de Santa Catarina (Epagri), em Itajaí, SC. No experimento conduzido nos Estados Unidos utilizou-se um Cambissolo Háplico Ta eutrófico verstissólico (CXbe) e, no experimento conduzido no Brasil, um Gleissolo Háplico típico (GXbd), denominados na classificação americana de Thermic Vertic Haplaquepts e Entisol Aeric Typic, respectivamente. Nos dois locais, as amostras de solo foram coletadas na camada superficial de 0 a $15 \mathrm{~cm}$ de áreas cultivadas com arroz irrigado, cujas propriedades encontram-se no quadro 1. Após a coleta, as amostras foram secas ao ar, passadas em peneira com malha de $0,5 \mathrm{~cm}$ de abertura e acondicionadas em baldes plásticos até atingirem uma camada de $15 \mathrm{~cm}$ de espessura, equivalente a $6,2 \mathrm{~kg}$ de solo seco por balde.

Quadro 1. Atributos químicos e teor de argila da camada $(0-15 \mathrm{~cm})$ de um Cambissolo utilizado no experimento conduzido no Estado do Mississippi - EUA e de um Gleissolo utilizado no experimento conduzido no Estado de Santa Catarina - Brasil

\begin{tabular}{lcccc}
\hline \multicolumn{1}{c}{ Solo } & $\mathbf{p H}-\mathrm{H}_{2} \mathbf{O}$ & $\mathbf{M O}^{(1)}$ & $\mathbf{C T C}_{\mathbf{p H} 7, \mathbf{0}^{(2)}}$ & Argila \\
\hline \multirow{2}{*}{ Cambissolo } & 7,5 & 20,0 & 32,0 & 630 \\
Gleissolo & 4,4 & 28,0 & 7,2 & 290 \\
\hline
\end{tabular}

(1) Matéria orgânica do solo. Determinado pelo método WalkleyBlack, descrito por Tedesco et al. (1995). (2) Capacidade de troca de cátions determinada com solução tamponada a pH 7,0. 
Foi aplicada ureia em diferentes formas, como segue: 1) testemunha com lâmina de água (sem N); 2) ureia adicionada sobre a superfície do solo úmido ( $80 \%$ da capacidade de campo), o qual permaneceu sem alagamento durante todo o período experimental; 3) ureia aplicada sobre a lâmina de água de alagamento, na forma sólida; 4) ureia previamente solubilizada em água deionizada e aplicada sobre a lâmina de água; 5) ureia incorporada, manualmente, na lama e o alagamento realizado logo em seguida; e 6) ureia aplicada sobre o solo úmido ( $80 \%$ da capacidade de campo), o qual foi alagado $48 \mathrm{~h}$ após. Nos tratamentos em que o solo foi alagado, a lâmina de água foi mantida numa espessura de $7,0 \mathrm{~cm}$, durante todo o período experimental. Foram utilizados $353 \mathrm{mg} \mathrm{N} /$ vaso, equivalente a $200 \mathrm{~kg} \mathrm{ha}^{-1}$ de $\mathrm{N}$, considerando a área superficial. Essa dose é maior do que a normalmente utilizada em lavouras de arroz e foi escolhida com o objetivo de fornecer valores analíticos mais facilmente detectáveis pelos equipamentos.

Para coletar a amônia volatilizada, foram utilizados tubos de PVC com $15 \mathrm{~cm}$ de diâmetro e $60 \mathrm{~cm}$ de altura. Os tubos foram introduzidos verticalmente no solo, dentro dos baldes, até atingirem o fundo destes, formando uma câmara. A ureia foi aplicada somente no solo que ficou do lado de dentro de cada tubo. Para coletar a amônia, foram colocados dois discos de esponja comercial dentro de cada tubo, com $2,5 \mathrm{~cm}$ de espessura e densidade de $24 \mathrm{~kg} \mathrm{~m}^{-3}$. Um disco foi colocado a $15 \mathrm{~cm}$ de altura em relação à lâmina de água; o outro foi colocado na parte superior deste, com o objetivo de evitar a contaminação com amônia proveniente da atmosfera. Antes de serem utilizadas, as esponjas foram lavadas com água e, em seguida, com ácido fosfórico $0,73 \mathrm{~mol} \mathrm{~L}^{-1} \mathrm{e}$, sequencialmente, enxaguadas com água deionizada e secas ao ar. Depois disso, elas receberam $20 \mathrm{~mL}$ de ácido fosfórico $0,73 \mathrm{~mol} \mathrm{~L}^{-1}$ contendo $30 \%$ de glicerina, cujo método está descrito detalhadamente por Cantarella et al. (2003).

As esponjas da parte inferior do tubo foram trocadas no primeiro e aos $3,6,9,13,17$ e 22 dias após a aplicação da ureia; as da parte superior permaneceram as mesmas durante todo o período do experimento. Após serem retiradas dos tubos, as esponjas foram acondicionadas em sacos plásticos vedados e guardadas em geladeira até o momento das análises. Para extração do fosfato de amônio formado, cada esponja foi saturada com $100 \mathrm{~mL}$ de $\mathrm{KCl} 1,0 \mathrm{~mol} \mathrm{~L}^{-1}$. Após $12 \mathrm{~h}$ em repouso, elas foram pressionadas manualmente, para retirada da solução. As determinações de amônio foram realizadas em aparelho Flow Solution III, na Mississippi State University, e em destilador semimicro Kjeldahl, conforme Tedesco et al. (1995), na Universidade do Estado de Santa Catarina, em Lages, SC. Além das perdas de amônia, determinaram-se também, no mesmo dia de cada troca das esponjas, o $\mathrm{pH}$ e a concentração de amônio na água que estava acima da superfície do solo. Portanto, no tratamento 6, constituído pela ureia aplicada sobre o solo úmido com alagamento $48 \mathrm{~h}$ depois, o pH e o amônio começaram a ser determinados a partir da segunda avaliação, pois no primeiro dia após a aplicação do adubo ele ainda não tinha água na superfície.

Foi utilizado o delineamento experimental completamente casualizado, com três repetições. Os resultados foram submetidos à análise de variância, e as médias, comparadas entre si pelo teste de Duncan $(\mathrm{p}<0,05)$.

\section{RESULTADOS E DISCUSSÃO}

A emissão de amônia variou com a forma de aplicação da ureia, e o comportamento foi similar nos dois solos (Figura 1). As perdas de $\mathrm{N}$ no tratamento onde não foi aplicado ureia (testemunha) foram insignificantes, atingindo, após 22 dias de avaliação, um total acumulado de 4 e $6 \mathrm{mg} / \mathrm{vaso}$ no Cambissolo e no Gleissolo (2,3 e $\left.3,4 \mathrm{~kg} \mathrm{ha}^{-1}\right)$, respectivamente, não tendo havido diferença entre os dois solos (Quadro 2). A volatilização ocorreu porque parte do $\mathrm{N}$ mineralizado transforma-se em amônia e se perde na atmosfera (Sangoi et al., 2003; Griggs et al., 2007).

A maior volatilização de amônia ocorreu quando a ureia foi aplicada sobre a lâmina de água, tanto na forma de solução quanto sólida, seguida pela aplicação em solo úmido sem alagamento; depois, pela ureia aplicada em solo úmido com alagamento 48 h após; e, por último, pela ureia incorporada ao solo alagado (Quadro 2). Dos $353 \mathrm{mg}$ de $\mathrm{N}$ aplicados sobre a lâmina de água na forma líquida, 122 e 137 mg/vaso volatilizaram no Cambissolo e no Gleissolo, respectivamente, correspondendo a 34 e $38 \%$ da quantidade de $\mathrm{N}$ aplicada (Quadro 2). Valores similares foram encontrados quando a ureia foi aplicada na forma de grânulos, em que as perdas foram de 104 e $132 \mathrm{~g} / \mathrm{vaso}$ no Cambissolo e no Gleissolo, respectivamente, correspondendo a 29 e $37 \%$ da quantidade de $\mathrm{N}$ aplicada (Quadro 2).

As altas perdas de $\mathrm{N}$ verificadas nos tratamentos em que a ureia foi aplicada sobre a lâmina de água, em ambos os solos, demonstram que a presença da água não inibiu a emissão da amônia para a atmosfera, apenas a retardou no Cambissolo. Considerando que neste experimento foi utilizada dose equivalente a $200 \mathrm{~kg} \mathrm{ha}^{-1} \mathrm{de} \mathrm{N}$, os percentuais de perdas acumuladas são inferiores aos encontrados por Fillery \& De Matta (1986), os quais verificaram perdas equivalentes a 11,27 e $47 \%$ pelo uso de ureia 

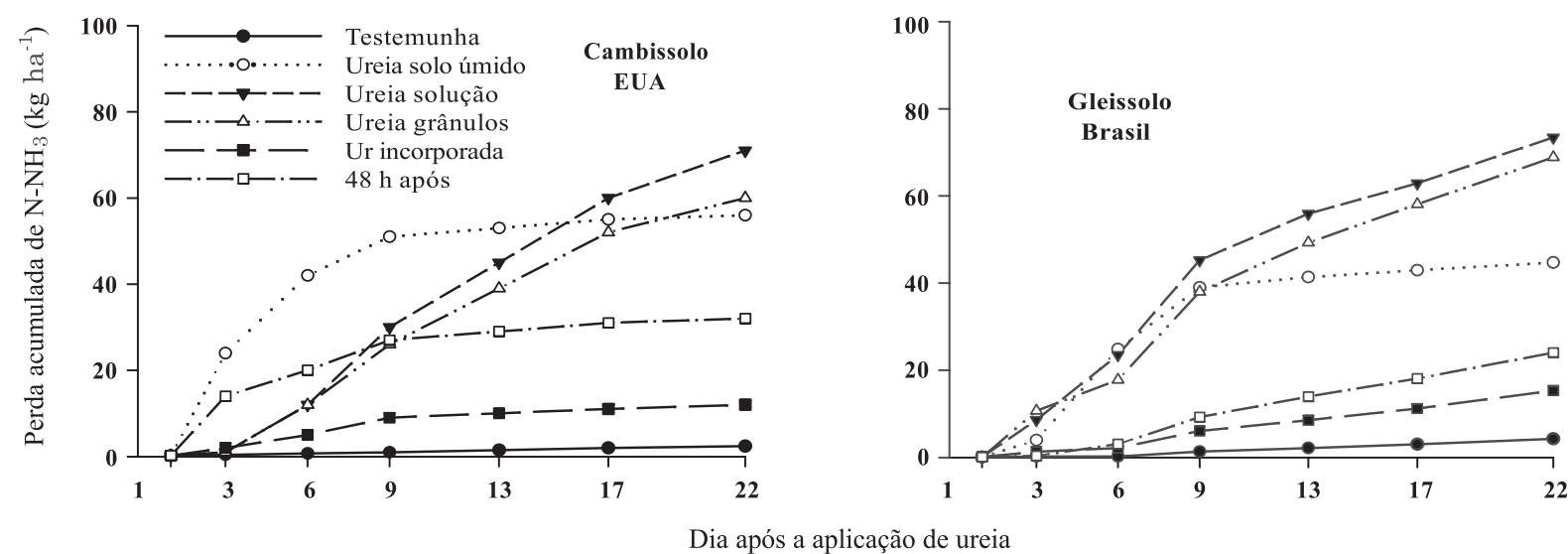

Figura 1. Perda acumulada de amônia em função do método de aplicação de ureia. Testemunha (sem N); ureia solo úmido: ureia aplicada sobre a superfície do solo úmido, sem alagamento durante todo o período de avaliação; ureia solução: ureia solubilizada em água deionizada e aplicada sobre a lâmina de água de alagamento do solo; Ureia grânulos: ureia aplicada sobre lâmina de água, na forma sólida; Ur. incorporada: ureia incorporada na lama com alagamento subsequente; $48 \mathrm{~h}$ após: ureia aplicada na superfície do solo úmido seguida de alagamento $48 \mathrm{~h}$ após a sua aplicação. Nos tratamentos com ureia foram aplicados $353 \mathrm{mg} / \mathrm{vaso}$ de $\mathrm{N}$, equivalente a $200 \mathrm{~kg} \mathrm{ha}^{-1} \mathrm{de} \mathrm{N}$.

Quadro 2. Perda acumulada de amônia durante os primeiros 22 dias após a aplicação de $353 \mathrm{mg}$ de $\mathrm{N}$ em função do método de aplicação de ureia em vasos, em um Cambissolo no Estado do Mississippi - EUA e em um Gleissolo no Estado de Santa Catarina - Brasil

Tratamento

Perdas de $\mathrm{N}-\mathrm{NH}_{3}$

Cambissolo (EUA) Gleissolo (Brasil)

\begin{tabular}{lcccc}
\hline & mg/vaso & $\%$ & mg/vaso & \\
Testemunha (sem N) & $4 \mathrm{dA}$ & - & $6 \mathrm{dA}$ & - \\
Ureia em solo úmido & $100 \mathrm{bA}$ & $28 \mathrm{bA}$ & $78 \mathrm{bB}$ & $22 \mathrm{bB}$ \\
Ureia em solução & $122 \mathrm{aB}$ & $34 \mathrm{aB}$ & $137 \mathrm{aA}$ & $38 \mathrm{aA}$ \\
Ureia em grânulos & $104 \mathrm{bB}$ & $29 \mathrm{bB}$ & $21 \mathrm{dA}$ & $37 \mathrm{aA}$ \\
Ureia incorporada & $14 \mathrm{~dB}$ & $4 \mathrm{~dB}$ & $35 \mathrm{cB}$ & $10 \mathrm{cB}$ \\
Alagamento 48 hapós & $52 \mathrm{cA}$ & $14 \mathrm{cA}$ & 5,2 & 5,2 \\
CV (\%) & 10,0 & 10,0 &
\end{tabular}

(1) Médias seguidas das mesmas letras não diferem entre si pelo teste de Duncan $(p<0,05)$. Letras minúsculas comparam os tratamentos dentro de cada coluna; letras maiúsculas comparam as perdas entre os solos para cada unidade (\% ou mg/vaso). Tratamentos: testemunha (sem N); ureia em solo úmido: ureia aplicada na superfície de solo úmido (80 \% da capacidade de campo) sem alagamento durante todo o período de avaliação; ureia em solução: ureia solubilizada em água deionizada e aplicada sobre lâmina de água; ureia em grânulos: ureia aplicada sobre lâmina de água, na forma sólida; ureia incorporada: ureia incorporada na lama com alagamento subsequente; alagamento 48 h após: ureia aplicada em solo úmido seguida de alagamento 48 h depois. Médias de três repetições. Nos tratamentos com ureia foram aplicados $353 \mathrm{mg} / \mathrm{vaso}$ de $\mathrm{N}$, equivalente a $200 \mathrm{~kg} \mathrm{ha}^{-1} \mathrm{de} \mathrm{N}$.

em cobertura, sobre lâmina de água, nas doses de 40,60 e $80 \mathrm{~kg} \mathrm{ha}^{-1}$ de N, respectivamente. Por outro lado, foram superiores aos $15 \%$ verificados por Duarte et al. (2007), que utilizaram dose equivalente a $100 \mathrm{~kg} \mathrm{ha}^{-1}$ de $\mathrm{N}$ em um Planossolo Hidromórfico do Rio Grande do Sul. Essas diferenças encontradas pelos autores, em diferentes locais, podem estar relacionadas às características de solo, como $\mathrm{pH}$ e CTC, e às condições climáticas, como temperatura e velocidade do vento, além das características da água, especialmente o $\mathrm{pH}$.
Houve diferenças nas perdas acumuladas de amônia entre os dois solos em todos os tratamentos que receberam ureia (Quadro 2). No Cambissolo, quando a ureia foi aplicada sobre a lâmina de água (tratamentos 2 e 3), a emissão de amônia iniciouse no 3 o dia e estendeu-se até o final do período de avaliação, enquanto no Gleissolo a emissão de amônia começou no 1 o dia após a aplicação da ureia e diminuiu de intensidade a partir do $13^{\circ}$ dia (Figura 1). Embora os dois solos estivessem alagados, no Cambissolo a lâmina de água provocou 
atraso na hidrólise da ureia, o que não ocorreu no Gleissolo. Esse fato pode ser atribuído à alta concentração de amônio na água do Gleissolo um dia após a adição da ureia (Figura 2). A rápida hidrólise da ureia no Gleissolo pode ter ocorrido em razão de este solo ter $40 \%$ a mais de matéria orgânica (MO) que o Cambissolo (2,8 e 2,0 \%, respectivamente), uma vez que altos conteúdos de MO aumentam a população microbiana, e esta, por sua vez, intensifica a atividade da urease, que catalisa a hidrólise da ureia (Sahrawat, 1983; Sangoi et al., 2003).

Quando a ureia foi aplicada em solo úmido, o qual permaneceu arejado durante todo o período de avaliação, foram perdidos 26 e $22 \%$ da quantidade de $\mathrm{N}$ aplicada no Cambissolo e no Gleissolo, respectivamente (Quadro 2). Nesse tratamento, a intensidade das emissões de amônia não teve o mesmo comportamento entre os dois solos. No Cambissolo, as emissões de amônia iniciaramse a partir do 1o dia após a aplicação de ureia e

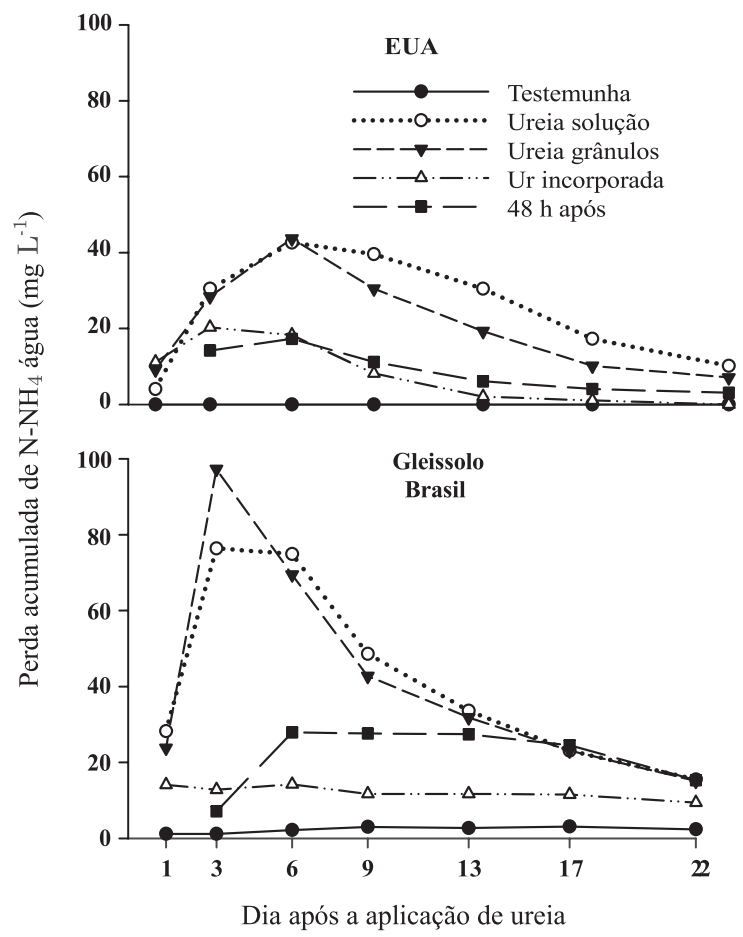

Figura 2. Concentração de amônio na água de alagamento dos solos em função do método de aplicação da ureia. Testemunha $(\operatorname{sem} N)$; ureia solução: ureia solubilizada em água deionizada e aplicada sobre a lâmina de água de alagamento do solo; ureia grânulos: ureia aplicada sobre lâmina de água de alagamento, na forma sólida; Ur incorporada: ureia incorporada na lama com alagamento subsequente; $48 \mathrm{~h}$ após: ureia aplicada na superfície do solo úmido seguida de alagamento $48 \mathrm{~h}$ após a sua aplicação. Nos tratamentos com ureia foram aplicados $353 \mathrm{mg} /$ vaso de $\mathrm{N}$, equivalente a $200 \mathrm{~kg} \mathrm{ha}^{-1}$ de $\mathrm{N}$. atingiram uma perda de $\mathrm{N}$ equivalente a $52 \mathrm{~kg} \mathrm{ha}^{-1}$, enquanto no Gleissolo as perdas iniciaram-se no terceiro dia e atingiram o equivalente a $44 \mathrm{~kg} \mathrm{ha}^{-1}$ (Figura 1). A antecipação da emissão de amônia no Cambissolo é atribuída ao elevado $\mathrm{pH}$ inicial desse solo (Quadro 1). Em ambos os solos, as emissões de amônia ocorridas no tratamento em que os solos não foram alagados cessaram aos nove dias após a aplicação da ureia (Figura 1). Isso ocorreu porque, para manter a umidade dos solos em $80 \%$ da capacidade de campo, foi adicionada água nove dias depois da aplicação de ureia. A aplicação de água nos solos favoreceu o deslocamento descendente da ureia e do amônio que estavam na superfície. O maior contato tanto da ureia quanto do amônio com o solo dificulta o deslocamento da amônia e favorece o contato dela com os íons $\mathrm{H}^{+}$do solo, diminuindo, dessa forma, a volatilização da amônia (Savant \& De Datta, 1980; Sangoi et al., 2003).

No tratamento em que os solos foram alagados $48 \mathrm{~h}$ após a aplicação da ureia, 14 e $10 \%$ do N aplicado foram perdidos no Cambissolo e no Gleissolo, respectivamente (Quadro 2). As menores perdas de amônia nesse tratamento, quando comparadas às perdas dos tratamentos com ureia aplicada sobre a lâmina de água e ureia aplicada em solo úmido sem alagamento, demonstram que a aplicação de ureia no solo seco com posterior alagamento é uma prática eficiente no aproveitamento do $\mathrm{N}$ da ureia pelo arroz irrigado. Scivittaro et al. (2005) verificaram perdas de amônia da ordem de $20 \%$ quando a ureia foi aplicada em um Planossolo Hidromórfico seco seguido de alagamento 10 dias depois e que, após a entrada da água, a emissão de amônia praticamente cessou. A perda de amônia no tratamento que foi alagado 48 h após a aplicação de ureia foi intensa a partir do 1o dia no Cambissolo e iniciou-se de forma mais moderada, a partir do terceiro dia, no Gleissolo, atingindo perda acumulada de $\mathrm{N}$ equivalente a 29,6 e 20,0 $\mathrm{kg} \mathrm{ha}^{-1}$ no Cambissolo e no Gleissolo, respectivamente (Figura 1). A diferença na intensidade de emissão de amônia nos primeiros dias após a aplicação de ureia é atribuída ao $\mathrm{pH}$ inicial de cada solo, visto que o Cambissolo possui $\mathrm{pH}$ alcalino e o Gleissolo, pH ácido (Quadro 1). Verifica-se, todavia, que, enquanto no Cambissolo a emissão de amônia diminuiu de intensidade a partir do nono dia, no Gleissolo ela se manteve de forma praticamente constante durante todo o período de avaliação. $\mathrm{O}$ decréscimo na intensidade da emissão de amônia no Cambissolo, ao longo do tempo, é atribuído à sua alta CTC (Quadro 1), visto que Kiehl (1989), estudando a distribuição e retenção de $\mathrm{NH}_{4}^{+}$em solos com características diferentes, constatou retenções equivalentes a 15,7 e 29,3\% dos $100 \mathrm{~kg} \mathrm{ha}^{-1}$ de $\mathrm{N}$ aplicados, em solo com baixa e alta CTC, respectivamente. 
A incorporação da ureia no solo alagado diminuiu substancialmente a emissão de amônia nos dois solos. Foram perdidos apenas 4,0 e $6,1 \%$ da quantidade de $\mathrm{N}$ aplicada no Cambissolo e no Gleissolo, respectivamente (Quadro 2). Essas baixas perdas são atribuídas, principalmente, às baixas concentrações de amônio na água de alagamento (Figura 2) e ao fato de o aumento do $\mathrm{pH}$ ao redor dos grânulos de ureia, durante a sua hidrólise, ter sido tamponado pelos íons $\mathrm{H}^{+}$existentes no solo (Savant et al., 1987; Ernani, 2008), além da adsorção do $\mathrm{NH}_{4}{ }^{+}$aos coloides do solo, diminuindo a sua movimentação em direção à superfície do solo. Perdas de amônia subsequentes à incorporação da ureia em solos alagados têm sido inferiores a $10 \%$ da quantidade aplicada (Mikkelsen, 1987; De Datta et al., 1989). No presente trabalho, por outro lado, embora os resultados tenham mostrado alta volatilização de amônia, não houve a presença de plantas, as quais poderiam alterar a dinâmica das reações do $\mathrm{N}$ após a hidrólise da ureia.

Os teores de amônio na água de alagamento dos solos foram altos nos primeiros dias após a aplicação da ureia e diminuíram com o passar do tempo, tendo havido comportamento diferencial entre os tratamentos e entre os solos (Figura 2). No tratamento sem aplicação de N (testemunha), os valores foram insignificantes nos dois solos. Já nos tratamentos que receberam ureia, as maiores concentrações de amônio na água ocorreram entre o terceiro e o nono dia após a aplicação do fertilizante e foram maiores naqueles com ureia aplicada sobre a lâmina de água, tanto na forma de solução como em grânulos, seguidas pela ureia aplicada em solo úmido com alagamento $48 \mathrm{~h}$ depois e, por último, pelo tratamento com ureia incorporada no solo alagado (Figura 2).

Nos tratamentos em que a ureia foi aplicada sobre a lâmina de água, a concentração máxima de amônio, no Cambissolo, foi de $42 \mathrm{mg} \mathrm{L}^{-1}$ e ocorreu no sexto dia; a partir desse tempo, começou a decrescer, de forma moderada (Figura 2); no Gleissolo, a máxima concentração de amônio na água ocorreu no terceiro dia após a aplicação do fertilizante, tendo atingido $100 \mathrm{mg} \mathrm{L}^{-1}$ quando a ureia foi aplicada na forma de grânulos e $80 \mathrm{mg} \mathrm{L}^{-1}$ quando ela foi aplicada na forma de solução. Entretanto, no Gleissolo, o decréscimo na concentração de amônio na água ocorreu de forma mais acentuada do que no Cambissolo (Figura 2). Quando a ureia é aplicada sobre a lâmina de água, após a sua hidrólise, há aumento da concentração de amônio. Durante a sua hidrólise, a ureia também promove o aumento do $\mathrm{pH}$ do meio, intensificando, dessa forma, as perdas de amônia por volatilização.

No tratamento em que os solos foram alagados $48 \mathrm{~h}$ após a aplicação de ureia, a máxima concentração de amônio na água ocorreu no sexto dia para os dois solos. Entretanto, no Cambissolo o pico atingiu $20 \mathrm{mg} \mathrm{L}^{-1}$ e começou a decrescer, enquanto no Gleissolo ele foi de $30 \mathrm{mg} \mathrm{L}^{-1}$ e mantevese praticamente uniforme até o $17^{\circ}$ dia (Figura 2). A principal causa dessas diferenças está na CTC dos solos (Quadro 1): a maior CTC do Cambissolo confere a ele maior capacidade de retenção de $\mathrm{NH}_{4}{ }^{+}$ do que o Gleissolo.

Após o alagamento dos solos, houve aumento do $\mathrm{pH}$ da água de todos os tratamentos (Figura 3). $\mathrm{Na}$ testemunha, o $\mathrm{pH}$ da água sobre o Cambissolo foi superior ao $\mathrm{pH}$ da água sobre o Gleissolo, e isso também ocorreu no $\mathrm{pH}$ da fase sólida (Quadro 1). Após o alagamento, as reações de redução normalmente aumentam o $\mathrm{pH}$ dos solos ácidos e diminuem o $\mathrm{pH}$ dos solos alcalinos (Ponnamperuma, 1972). No Gleissolo, o pH do tratamento que não recebeu $\mathrm{N}$ teve elevação constante até o final das avaliações; no Cambissolo, o pH da água começou a decrescer 17 dias após o alagamento (Figura 3).

Quando a ureia foi aplicada sobre a lâmina de água, tanto na forma sólida quanto líquida, o $\mathrm{pH}$ da água existente sobre o Cambissolo atingiu valores próximos a 9,0, aos nove dias após a aplicação do fertilizante, e permaneceu praticamente constante durante os 22 dias de avaliação; no Gleissolo, o valor máximo ocorreu no terceiro dia, tendo atingido $\mathrm{pH}$ em torno de 8,4 , seguido de um pequeno decréscimo e estabilização em, aproximadamente, 7,7 (Figura 3). No Cambissolo, o coeficiente de correlação (r) entre a concentração de amônio e o $\mathrm{pH}$ da água sobre o solo, nos primeiros seis dias após a aplicação de ureia, foi de 0,87 para as duas formas de ureia, o qual decresceu com o passar do tempo, tendo atingido 0,39 para a ureia aplicada na forma líquida e 0,06 para a forma sólida, aos 22 dias após o alagamento, ambos não estatisticamente significativos a $5 \%$ (dados não apresentados). No Gleissolo, os coeficientes de correlação (r) entre essas variáveis foram de 0,90 para a ureia aplicada na forma líquida e 0,80 para a forma sólida, até nove dias depois da aplicação do fertilizante; após esse período, os coeficientes diminuíram até atingir 0,75 e 0,68, aos 22 dias após a aplicação de ureia líquida e sólida, respectivamente (dados não apresentados). A diminuição no valor desses coeficientes de correlação ocorreu porque, nos primeiros dias após a aplicação de ureia, a hidrólise dessa molécula aumenta o $\mathrm{pH}$ do meio, de acordo com as seguintes reações $\left[\mathrm{CO}\left(\mathrm{NH}_{2}\right)_{2}+2 \mathrm{H}_{2} \mathrm{O} \rightarrow\left(\mathrm{NH}_{4}\right)_{2} \mathrm{CO}_{3}\right)$ e $\left.\left(\mathrm{NH}_{4}\right)_{2} \mathrm{CO}_{3}+\mathrm{H}_{2} \mathrm{O} \rightarrow 2 \mathrm{NH}_{4}{ }^{+}+\mathrm{OH}^{-}+\mathrm{HCO}_{3}^{-}\right]$. O pico de máxima hidrólise e consequente amonificação da ureia praticamente coincidiu com o maior valor do $\mathrm{pH}$ da água. Todavia, o amônio formado passa a difundir no solo, diminuindo sua concentração na água, enquanto o $\mathrm{pH}$ da água praticamente se 


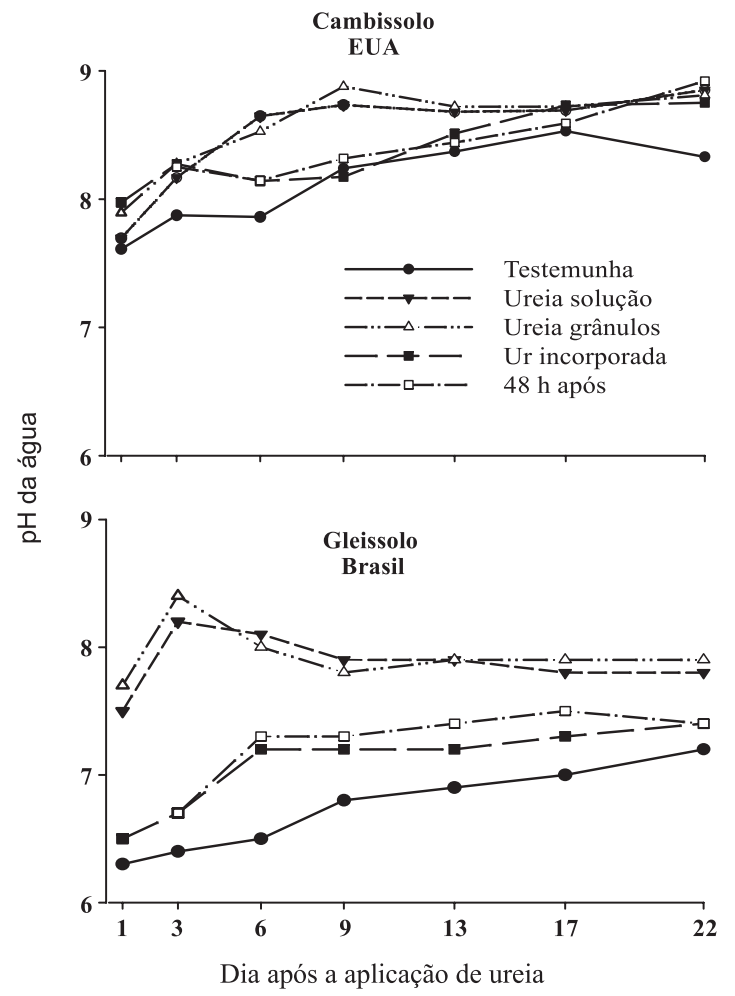

Figura 3. pH da água de alagamento dos solos em função do método de aplicação de ureia. Testemunha (sem N); ureia solução: ureia solubilizada em água deionizada e aplicada sobre a lâmina de água de alagamento do solo; ureia grânulos: ureia aplicada sobre lâmina de água de alagamento, na forma sólida; Ur incorporada: ureia incorporada na lama com alagamento subsequente; $48 \mathrm{~h}$ após: ureia aplicada na superfície do solo úmido seguida de alagamento $48 \mathrm{~h}$ após a aua aplicação. Nos tratamentos com ureia foram aplicados $353 \mathrm{mg} /$ vaso de $\mathrm{N}$, equivalente a $200 \mathrm{~kg} \mathrm{ha}^{-1}$ de $\mathrm{N}$.

mantém estável. No tratamento em que a ureia foi aplicada no solo seco e o alagamento foi realizado $48 \mathrm{~h}$ após, o coeficiente de correlação (r) entre a concentração de amônio na água de alagamento e o $\mathrm{pH}$ desta, até os nove dias, foi de -0,55 no Cambissolo e 0,94 no Gleissolo. Essa diferença entre os solos é devida ao $\mathrm{pH}$ inicial, tanto da fase sólida dos solos quanto da água que permanece sobre eles, que no Cambissolo eram alcalinos e, no Gleissolo, ácidos. No tratamento sem $\mathrm{N}$ e naquele em que a ureia foi incorporada na lama, os coeficientes de correlação foram inconsistentes porque neles o aumento do $\mathrm{pH}$ da água ocorreu devido às reações de oxirredução do solo e não à hidrólise da ureia.

$\mathrm{O} \mathrm{pH}$ da água de alagamento é de grande importância na intensidade de emissão de amônia. Buresh (2008) verificaram que a amônia aquosa encontrava-se em teores insignificantes quando o $\mathrm{pH}$ da água era de 7,5 , porém aumentou rapidamente com o aumento do $\mathrm{pH}$, atingindo concentração igual à de $\mathrm{NH}_{4}{ }^{+}$quando o pH atingiu 9,2. Mikkelsen (1987) verificou que a concentração de $\mathrm{NH}_{3}$ na água de alagamento do arroz aumentou 10 vezes quando o pH desta passou de 7,5 para 9,5. Diante dessas referências, esperava-se que a volatilização de amônia no Cambissolo fosse muito superior àquela quantificada no Gleissolo. Entretanto, a CTC do Cambissolo era praticamente quatro vezes maior do que a do Gleissolo (Quadro 1), o que deve ter minimizado as emissões de amônia no Cambissolo. Portanto, embora o $\mathrm{pH}$ da água do Cambissolo pudesse ter favorecido a emissão de amônia, a sua alta CTC deve ter atuado como um fator atenuante dessas emissões, resultando num certo equilíbrio nos valores das perdas de amônia nos dois solos (Quadro 2).

\section{CONCLUSÕES}

1. A lâmina de água que permanece na superfície de solos alagados não evita a volatilização de amônia após a aplicação de ureia.

2. A volatilização de amônia é menor quando a ureia é aplicada em solo seco seguida de alagamento do que quando ela é aplicada sobre a lâmina de água.

3. Quando a ureia é incorporada na lama com alagamento subsequente, as perdas de $\mathrm{N}$ por volatilização de amônia são insignificantes.

4. Para evitar excessiva perda de $\mathrm{N}$ por volatilização, em solos alagados, a ureia deve ser aplicada na lama ou em solo, seguida de alagamento imediato.

5. No cultivo do arroz irrigado em sistema pré-germinado, realizado em Santa Catarina, as lavouras são drenadas em duas ocasiões: aproximadamente três semanas após a semeadura, para permitir a aplicação de herbicida, e em torno dos 45 a 60 dias após a semeadura, com os objetivos de aumentar a capacidade de suporte das máquinas e equipamentos para a colheita dos grãos e diminuir o acamamento das plantas. Portanto, são duas ocasiões em que a ureia pode ser aplicada no solo drenado com alagamento subsequente, diminuindo, dessa forma, as perdas de $\mathrm{N}$ por volatilização de amônia.

\section{LITERATURA CITADA}

BURESH, R.J. Site-specific nutrient management for rice. Farming Outlook, June,18-23, 2008. 
CANTARELA, H. Nitrogênio. In: NOVAIS. R.F.; ALVAREZ V., V.H.; BARROS, N.F.; FONTES, R.L.F.; CANTARUTTI, R.B. \& NEVES, J.C.L. eds. Fertilidade do solo. Viçosa, MG, Sociedade Brasileira de Ciência do Solo, 2007. p.375-470.

CANTARELLA, H.; MATTOS JR., D.; QUAGGIO, J.A. \& RIGOLIN, A.T. Fruit yield of Valencia sweet orange fertilized with different $\mathrm{N}$ sources and the loss of applied N. Nutr. Cycling Agroec., 67:215-223, 2003.

COMISSÃO DE FERTILIDADE DO SOLO - CQFSRS/SC. Recomendações de adubação e calagem para os estados do Rio Grande do Sul e Santa Catarina. 3.ed. Passo Fundo, Sociedade Brasileira de Ciência do Solo/Núcleo Regional Sul, 1995. 224p.

COMISSÃO DE QUÍMICA E FERTILIDADE DO SOLO CQFSRS/SC. Manual de adubação e de calagem para os estados do Rio Grande do Sul e de Santa Catarina. 10.ed. Porto Alegre, Sociedade Brasileira de Ciência do Solo/ Núcleo Regional Sul, 2004. 400p.

De DATTA, S.K.; TREVITT, A.C.F. \& FRENEY, J.R. Measuring nitrogen losses from lowland rice using bulk aerodynamic and nitrogen -15 balance methods. Soil Sci. Soc. Am. J., $53: 1275-1281,1989$

DUARTE, F.M.; PKOJESKI, E.; SILVA, L.S. \& GRAUPE, F.A. Perdas de nitrogênio por volatilização de amônia com aplicação de uréia em solo de várzea com diferentes níveis de umidade. Ci. Rural, 37:705-711, 2007.

ERNANI, P.R. Química do solo e disponibilidade de nutrientes. Lages, 2008. 230p.

FAGERIA, N.K.; SLATON, N.A. \& BALIGAR, V.C. Nutrient management for improving lowland rice productivity and sustainability. Adv. Agron., 80:63-152, 2003.

FILLERY, I.R.P. \& De DATTA, S.K. Ammonia volatilization from nitrogen sources applied to rice fields. I. Methodology, ammonia fluxes and nitrogen-15 loss. Soil Sci. Soc. Am. J., 48:80-86, 1986 .

GRIGGS, B.R.; WILSON, R.J. \& SLATON, C.E. Ammonia volatilization and nitrogen uptake for conventional and conservation tilled dry-seeded, delayed-flood rice. Soil Sci. Soc. Am. J., 71:745-751, 2007.

HAYASHI, K.; NISHIMURA, S. \& YAGI, K. Ammonia volatilization from the surface of a Japanese paddy field during rice cultivation. Jap. Soc. Soil Sci. Plant Nutr., 52:545-555, 2006.

IRGA - Instituto Rio Grandense do Arroz. Arroz Irrigado: Recomendações Técnicas da Pesquisa para o Sul do Brasil/ IRGA. Porto Alegre, RS. 2001. 128p

ISHERWOOD, K.F. Mineral fertilizer use and the environment. Paris: International Fertilizer Industry Association, 2003. 63p.

KIEHL, J.C. Distribuição e retenção de amônia no solo após a aplicação de ureia. R. Bras. Ci. Solo, 13:75-80, 1989.
LINDAU, C.W.; REDDY, K.R.; LU, W. \& KHIND, C.S. Effect of redox potential on urea hydrolysis and nitrification in soil suspensions. Soil Sci., 148:184-190, 1989.

MATTOS, M.L.T. Carbono e nitrogênio da biomassa e atividade microbiana em um solo cultivado com arroz irrigado orgânico e manejado com diferentes adubos verdes. Pelotas, Embrapa Clima Temperado, 2004. p.9-18. (Documentos, 16)

MIKKELSEN, D.S. Nitrogen budgets in flooded soils used for rice production. Plant Soil, 100:71-77, 1987.

PONNAMPERUMA, F.N. The chemistry of submerged soils. Adv. Agron., 24:29-96, 1972.

REDDY, K.R. \& PATRICK, J.R. Fate of fertilizer nitrogen in the rice root zone. Soil Sci. Soc. Am. J., 50:649-651, 1986.

SAHRAWAT, K.L. Relationship between soil urease activity and other properties of some tropical wetland rice soils. Nutr. Cycling Agroec., 4:145-150, 1983.

SANGOI, L.; ERNANI, P.R.; LECH, V.A. \& RAMPAZZO, C. Volatilização de $\mathrm{N}-\mathrm{NH}_{3}$ em decorrência da forma de aplicação de uréia, manejo de resíduos e tipo de solo, em laboratório. Ci. Rural, 33:687-692, 2003.

SAVANT, N.K. \& De DATTA, S.K. Movement and distribution of ammonium following deep placement of urea in a wetland rice soil. Soil Sci. Soc. Am. J., 44:559-565, 1980.

SAVANT, N.K.; JAMES, A.F. \& McCLEAN, G.H. Effect of amounts and sequence of additions of urea and water on hydrolysis of surface-applied granular urea in unsaturated soils. Fertilizer Research, v.11, 1987. p.231-234.

SCIVITTARO, W.B.; SILVA, C.A.S.; ANDRES, A.; OLIVEIRA, A.P.B.B.; ÁVILA, M.S.V.; MURAOKA, T. \& TRIVELIN, P.C.O. Dinâmica do nitrogênio em sistema de produção de arroz irrigado. In: CONGRESSO DA CADEIA PRODUTIVA DE ARROZ, 1 ; REUNIÃO NACIONAL DE PESQUISA DE ARROZ, 7. Florianópolis. Anais. Santo Antônio de Goiás, Embrapa Arroz e Feijão, 2002. p.543-546.

SCIVITTARO, W.B.; GOMES, A.S. \& LIMA, F.S. Perdas de nitrogênio por volatilização de amônia em cultivo de arroz irrigado. . In: REUNIÃO DA CULTURA DO ARROZ IRRIGADO, 26.; CONGRESSO DE ARROZ IRRIGADO, 4., Santa Maria, 2005. Anais... Santa Maria, SOSBAI, 2005. p.477-480.

SOCIEDADE SUL-BRASILEIRA DE ARROZ IRRIGADO - SOSBAI. Arroz irrigado: recomendações técnicas da pesquisa para o sul do Brasil. In: REUNIÃO TÉCNICA SUL-BRASILEIRA DE ARROZ, 1., Porto Alegre, 2010. Anais... Porto Alegre, SOSBAI, 2010. 181p.

TEDESCO, M. J.; VOLKWEISS, S.J. \& BOHNEN, H. Análise de solo, planta e outros materiais. 2.ed. Porto Alegre, Departamento de Solos. Faculdade de Agronomia, UFRGS, 1995. 174p. (Boletim técnico, 5)

VLECK, P.L.G. \& CRASWELL, E.T. Ammonia volatilization from flooded soils. Fert. Res., 2:27-245, 1981.

WATANABE, T.; SON, T.T.; HUNG, N.N.; TRUONG, N.V.; GIAU, T.Q.; HAYASHI, K. \& ITO, O. Measurement of ammonia volatilization from flooded paddy fields in Vietnam. Jap. Soc. Soil Sci. Plant Nutr., 55:793-799, 2009. 
